\title{
The effect of oxygen and volatile combustibles on the sulphation of gaseous $\mathrm{KCl}$
}

\author{
Håkan Kassman a,b,*, Fredrik Normann a ${ }^{\mathrm{a}}$, Lars-Erik Åmand ${ }^{\mathrm{a}}$ \\ ${ }^{a}$ Chalmers University of Technology, Department of Energy and Environment, Gothenburg, Sweden \\ ${ }^{\mathrm{b}}$ Vattenfall Research E Development AB, Nyköping, Sweden
}

\section{A R T I C L E I N F O}

\section{Article history:}

Received 5 December 2011

Received in revised form 14 January 2013

Accepted 19 April 2013

Available online 24 May 2013

\section{Keywords:}

Sulphation

$\mathrm{KCl}$

IACM

Ammonium sulphate

Modelling

Combustion of biomass

\begin{abstract}
A B S T R A C T
Sulphur/sulphate containing additives, such as elemental sulphur (S) and ammonium sulphate $\left.\left(\mathrm{NH}_{4}\right)_{2} \mathrm{SO}_{4}\right)$, can be used for sulphation of $\mathrm{KCl}$ during biomass combustion. These additives convert $\mathrm{KCl}$ to an alkali sulphate and a more efficient sulphation is normally achieved for ammonium sulphate compared to sulphur. The presence of $\mathrm{SO}_{3}$ is thus of greater importance than that of $\mathrm{SO}_{2}$. Oxygen and volatile combustibles could also have an effect on the sulphation of gaseous $\mathrm{KCl}$. This paper is based on results obtained during co-combustion of wood chips and straw pellets in a $12 \mathrm{MW}$ circulating fluidised bed (CFB) boiler. Ammonium sulphate was injected at three positions in the boiler i.e. in the upper part of the combustion chamber, in the cyclone inlet, and in the cyclone. The sulphation of $\mathrm{KCl}$ was investigated at three air excess ratios $(\lambda=1.1,1.2$ and 1.4). Several measurement tools were applied including IACM (on-line measurements of gaseous alkali chlorides), deposit probes (chemical composition in deposits collected) and gas analysis. The position for injection of ammonium sulphate had a great impact on the sulphation efficiency for gaseous $\mathrm{KCl}$ at the different air excess ratios. There was also an effect of oxygen on the sulphation efficiency when injecting ammonium sulphate in the cyclone. Less gaseous $\mathrm{KCl}$ was reduced during air excess ratio $\lambda=1.1$ compared to the higher air excess ratios. The optimal position and conditions for injection of ammonium sulphate were identified by measuring $\mathrm{KCl}$ with IACM. A correlation was observed between the sulphation of gaseous $\mathrm{KCl}$ and reduced chlorine content in the deposits. The experimental observations were evaluated using a detailed reaction mechanism. It was used to model the effect of volatile combustibles on the sulphation of gaseous $\mathrm{KCl}$ by $\mathrm{SO}_{3}$. The calculations supported the proposition that the presence of combustibles at the position of $\mathrm{SO}_{3}$ injection (i.e. AS) causes reduction of $\mathrm{SO}_{3}$ to $\mathrm{SO}_{2}$.
\end{abstract}

(c) 2013 The Combustion Institute. Published by Elsevier Inc. All rights reserved.

\section{Introduction}

High levels of potassium chloride $(\mathrm{KCl})$ in flue gas can enhance deposit formation [1] and a high content of $\mathrm{KCl}$ in the deposits may accelerate superheater corrosion [2]. Biomass generally contains high amounts of alkali (mainly potassium, $\mathrm{K}$ ) and in some biomass fuels, such as straw, the chlorine $(\mathrm{Cl})$ content is also rather high. Potassium is released by primary reactions during devolatilisation and by secondary reactions during char combustion [3]. In the gas phase, $\mathrm{K}$ is mainly present as $\mathrm{KCl}$ and $\mathrm{KOH} . \mathrm{KCl}$ is dominant when the $\mathrm{Cl}$ content in the fuel mix is high $[3,4]$. Chlorine is mainly released as hydrogen chloride $(\mathrm{HCl})$ or as metal chlorides, such as $\mathrm{KCl}$. There are known interactions between the volatile

\footnotetext{
* Corresponding author at: Vattenfall Research \& Development AB, Nyköping, Sweden.

E-mail address: hakan.kassman@vattenfall.com (H. Kassman).
}

combustibles and trace species, including $\mathrm{K}$, sulphur $(\mathrm{S}), \mathrm{Cl}$, and nitrogen $(\mathrm{N})$ during combustion [5].

Deposit formation and superheater corrosion can be reduced by the presence of sulphur in the flue gas. Sulphur reacts with $\mathrm{KCl}$, converting it to a less corrosive alkali sulphate. However, the content of sulphur is normally relatively low in biomass fuels. Sulphur may be introduced either by co-combustion or as an additive, such as elemental sulphur and ammonium sulphate. Coal, peat and municipal sewage sludge (MSS) are among the sulphur-containing fuels suitable for co-combustion with biomass [6-10]. In [7,1013] results are presented from experiments when using elemental sulphur (S) and/or ammonium sulphate (AS, $\left.\left(\mathrm{NH}_{4}\right)_{2} \mathrm{SO}_{4}\right)$. These additives were evaluated in [13] for sulphation of gaseous $\mathrm{KCl}$. Ammonium sulphate lowered the concentration of gaseous $\mathrm{KCl}$ and simultaneously reduced the chlorine content in the deposits significantly better than sulphur.

The present work investigates the influence of oxygen and volatile combustibles on the sulphation of gaseous $\mathrm{KCl}$ by ammonium sulphate. The understanding of these interactions is of great 
importance in order to obtain an optimal sulphation efficiency from AS. The sulphation is investigated by technical scale experiments and the findings and discussion are supported by modelling using a gas-phase kinetic reaction mechanism of the $\mathrm{KCl}$ sulphation. The experimental work was carried out in a full-scale CFB boiler. The influence of oxygen was investigated at three air excess ratios $(\lambda=1.1,1.2$ and 1.4$)$ during injection of ammonium sulphate. The impact of volatile combustibles (hereafter expressed as combustibles) was investigated by injecting increasing amounts of AS in a sequence at two positions in the boiler and also in the hot cyclone. The composition of the flue gas in each position was characterised by measuring the concentration of several gas components including $\mathrm{KCl}$, carbon monoxide and hydrocarbons. The alkali/sulphur and combustion chemistry was modelled using two sets of detailed kinetic mechanisms [14,15].

\section{Sulphation of gaseous $\mathrm{KCl}$}

Both homogeneous (gas phase) and heterogeneous (liquid or solid phase) mechanisms have been proposed for the formation of alkali sulphates from alkali chlorides found in deposits or in ash particles $[5,15,16]$. The heterogeneous sulphation is not a part of the present investigation and is discussed in more detail in [13]. The homogeneous mechanism involves the formation of an alkali sulphate aerosol in the gas phase $[5,17]$. The overall reactions of the homogeneous mechanism may be described as follows: $\mathrm{KCl}$ is primarily sulphated by $\mathrm{SO}_{3}$ through the gas-phase reaction,

$2 \mathrm{KCl}+\mathrm{SO}_{3}+\mathrm{H}_{2} \mathrm{O} \rightarrow \mathrm{K}_{2} \mathrm{SO}_{4}+2 \mathrm{HCl}$

In turn, $\mathrm{SO}_{3}$ is formed either from oxidation of $\mathrm{SO}_{2}$,

$\mathrm{SO}_{2}+1 / 2 \mathrm{O}_{2} \leftrightarrow \mathrm{SO}_{3}$

or directly during injection of ammonium sulphate

$\left(\mathrm{NH}_{4}\right)_{2} \mathrm{SO}_{4} \rightarrow 2 \mathrm{NH}_{3}+\mathrm{SO}_{3}+\mathrm{H}_{2} \mathrm{O}$

$\mathrm{SO}_{2}$ is the major sulphur species during combustion and forms from fuel bound sulphur or from elemental sulphur if used as an additive. The sulphation rate in the gas phase is limited by the formation of $\mathrm{SO}_{3}$, i.e. the oxidation of $\mathrm{SO}_{2}$ to $\mathrm{SO}_{3}$ (Reaction (R2)) is the rate-limiting step [14,18-20]. Injection of AS gives a fast route for $\mathrm{SO}_{3}$ formation in the present work and the interactions between combustibles and $\mathrm{SO}_{3}$ may be investigated. Kassman et al. [13] recently confirmed that sulphation of gaseous $\mathrm{KCl}$ is more efficient in the presence of sulphur trioxide $\left(\mathrm{SO}_{3}\right)$ rather than sulphur dioxide $\left(\mathrm{SO}_{2}\right)$.

During combustion, interactions occur between the $\mathrm{CH}$ oxidation and the chemistry of $\mathrm{K}, \mathrm{S}$ and $\mathrm{Cl}$ [5]. Many of these interactions concern the so-called "chain carrying radicals", which include the hydroxyl $(\mathrm{OH})$, oxygen $(\mathrm{O})$ and hydrogen $(\mathrm{H})$ radical. The chain branching reaction,

$\mathrm{H}+\mathrm{O}_{2} \leftrightarrow \mathrm{OH}+\mathrm{O}$

is the most important reaction for radical production during combustion. The light volatile hydrocarbons, such as methane and ethene, are oxidised in a series of steps by the chain carrying radicals. Finally $\mathrm{CO}$ is formed in the last step before $\mathrm{CO}_{2}$ during this oxidation. $\mathrm{CO}$ is further oxidised to $\mathrm{CO}_{2}$ mainly by a hydroxyl radical,

$\mathrm{CO}+\mathrm{OH} \leftrightarrow \mathrm{CO}_{2}+\mathrm{H}$

feeding a hydrogen radical to the important Reaction (R4). The reaction between hydrocarbon radicals and chain carrying radicals is normally faster than Reaction (R5) [21]. This leads to an accumulation of $\mathrm{CO}$, which starts to oxidise when the hydrocarbon oxidation is completed. Thus, the presence of combustibles has a large influence over the radical pool.
The oxidation of $\mathrm{SO}_{2}$ to $\mathrm{SO}_{3}$ (global Reaction (R2)) involves recombination of $\mathrm{SO}_{2}$ with $\mathrm{O}$ or $\mathrm{OH}$ radicals and it may involve $\mathrm{HOSO}_{2}$ as an intermediate (Reaction (R7)) [22],

$\mathrm{SO}_{2}+\mathrm{O} \leftrightarrow \mathrm{SO}_{3}$

$\mathrm{SO}_{2}+\mathrm{OH} \leftrightarrow \mathrm{HOSO}_{2}$

$\mathrm{HOSO}_{2}+\mathrm{O}_{2} \leftrightarrow \mathrm{SO}_{3}+\mathrm{HO}_{2}$

and $\mathrm{SO}_{3}$ may be reduced by $\mathrm{H}$ radicals,

$\mathrm{SO}_{3}+\mathrm{H} \leftrightarrow \mathrm{SO}_{2}+\mathrm{OH}$

(R8) is a fast reaction and the presence of $\mathrm{H}$ radicals can thus have a great influence on the efficiency of the sulphation of gaseous $\mathrm{KCl}$ through its influence on $\mathrm{SO}_{3}$. Calculations concerning the reactions of $\mathrm{SO}_{3}$ with the $\mathrm{O} / \mathrm{H}$ radical pool were presented in [23]. Furthermore, the presence of $\mathrm{KCl}$ may consume $\mathrm{OH}$ radicals and inhibit oxidation of CO (Reaction (R5)) [21].

\section{Methodology}

\subsection{Research boiler and operating conditions}

The experiments were performed in the $12 \mathrm{MW}$ CFB boiler at Chalmers University of Technology shown in Fig. 1. This boiler is mainly used for research purposes and offers the possibility to perform measurement campaigns in a full scale boiler, while maintaining control over important operation parameters such as load, air supply and composition of the fuel mix. The boiler has been described earlier in several publications including $[8,10,13,24,25]$. The combustion chamber has a cross-section of approximately $2.25 \mathrm{~m}^{2}$ and a height of $13.6 \mathrm{~m}$. Fuel is fed from a fuel chute (located at the front of the boiler) to the lower part of the combustion chamber. The bed material is recirculated through the cyclone back to the combustion chamber. Meanwhile the combustion gases enter the convection pass where the gases are cooled down to $150{ }^{\circ} \mathrm{C}$ before cleaning in a secondary cyclone and a bag house filter.

Measurements were carried out during three air excess ratios $(\lambda=1.1,1.2$ and 1.4). Selected operating conditions for each air excess ratio are presented in Table 1 . Silica sand $\left(d_{p}=0.3 \mathrm{~mm}\right)$ was used as bed material. The fuel properties are presented in Table 2 . The base fuel was wood chips (made from stem wood). Straw pellets (made from wheat straw and manufactured in Köge, Denmark) were used as additional fuel, to increase the level of gaseous $\mathrm{KCl}$. The fraction of straw pellets was about $20-35 \%$ of the energy input to the boiler. The chlorine content in the straw pellets was much higher than in the wood chips. The potassium content on ash basis was about the same in the two biofuels. However, since the ash content was significantly higher in the straw, the loading of $\mathrm{K}$ increased with the fraction of straw. The higher levels of potassium in the bed could have caused bed agglomeration but a minor flow of $15-20 \mathrm{~kg} / \mathrm{h}$ of kaolin was introduced to the lower part of the combustion chamber through the return leg from the hot cyclone (14 in Fig. 1) in order to prevent agglomeration [24].

\subsection{Experimental procedure}

An aqueous solution of ammonium sulphate (AS) was injected into the boiler according to two experimental procedures. The first procedure, a so-called "transient test", was carried out for the three excess air ratios. The main purpose of the transient test was to investigate whether the presence of combustibles (i.e. CO and unburned hydrocarbons) have an impact on the sulphation efficiency of gaseous $\mathrm{KCl}$. Increasing amounts of AS were injected in a sequence at three positions in the boiler. The positions were in the 


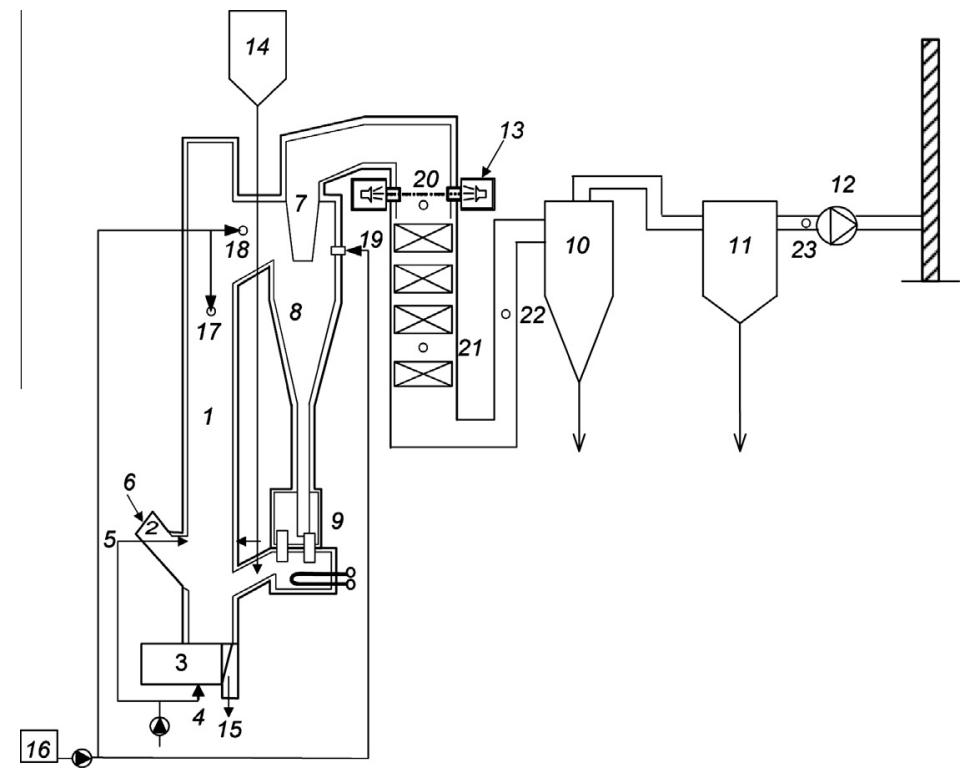

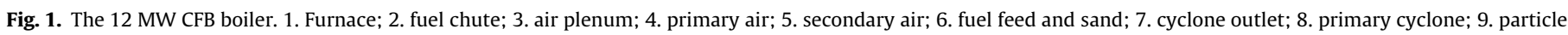

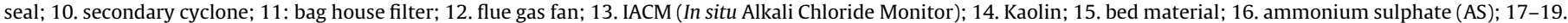

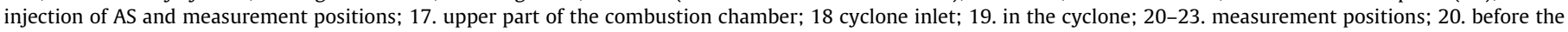
convection pass; 21 . in the convection pass, 22 . after the convection pass; 23 . before the stack.

Table 1

Operating parameters (average during each air excess ratio).

\begin{tabular}{llll}
\hline Parameter & $\lambda=1.1$ & $\lambda=1.2$ & $\lambda=1.4$ \\
\hline Load (MW) & 6.5 & 5.9 & 5.3 \\
Fraction of straw pellets,\% of load & 21.3 & 22.0 & 33.1 \\
Bed temperature $\left({ }^{\circ} \mathrm{C}\right)$ & 833 & 838 & 867 \\
Temperature, top of furnace $\left({ }^{\circ} \mathrm{C}\right)$ & 872 & 877 & 898 \\
Temperature, cyclone inlet $\left({ }^{\circ} \mathrm{C}\right)$ & 882 & 878 & 882 \\
Temperature, top of cyclone $\left({ }^{\circ} \mathrm{C}\right)$ & 888 & 864 & 828 \\
Temperature, cyclone outlet $\left({ }^{\circ} \mathrm{C}\right)$ & 884 & 861 & 836 \\
Temperature, before conv. pass $\left({ }^{\circ} \mathrm{C}\right)$ & 862 & 836 & 803 \\
Temperature, after bag filter $\left({ }^{\circ} \mathrm{C}\right)$ & 167 & 165 & 168 \\
Pressure drop in furnace $(\mathrm{kPa})$ & 6.2 & 6.3 & 6.3 \\
Excess air ratio & 1.12 & 1.22 & 1.36 \\
Total air flow to combustor $(\mathrm{kg} / \mathrm{s})$ & 2.71 & 2.70 & 2.72 \\
Primary air flow $(\mathrm{kg} / \mathrm{s})$ & 1.46 & 1.44 & 1.47 \\
Secondary air, total flow $(\mathrm{kg} / \mathrm{s})$ & 0.64 & 0.63 & 0.64 \\
Flue gas recirculation $(\mathrm{kg} / \mathrm{s})$ & 0.77 & 0.63 & 0.38 \\
Primary air/total air flow $(\%)$ & 53.8 & 53.3 & 54.2 \\
Fluidisation velocity $(\mathrm{m} / \mathrm{s})$ & 5.9 & 5.6 & 5.0 \\
Bed turnover $(\mathrm{kg} / \mathrm{MW} \mathrm{h})$ & 1.15 & 1.4 & 1.5 \\
\hline
\end{tabular}

upper part of the combustion chamber (17 in Fig. 1), in the cyclone inlet (18), and in the cyclone (19). The gas temperatures in these positions were measured by means of a suction pyrometer and can be found in Table 1 (top of furnace, cyclone inlet and top of cyclone). Table 3 shows experimental parameters (i.e. molar flows of $\mathrm{S}$ and molar ratios of $\mathrm{S} / \mathrm{Cl}$ ) and tests performed for the sequences at these positions for excess air ratio $\lambda=1.2$. Each sequence consisted of a reference without any injection of AS (Ref), and injection of increasing amounts of AS (i.e. molar ratios of $\mathrm{S} / \mathrm{Cl}$ ) in $\mathrm{AS} 1, \mathrm{AS} 2$, AS3, AS4, AS5, AS6 and each of them was performed for $25 \mathrm{~min}$.

The purpose of the second experimental procedure was to investigate the influence of oxygen on the sulphation of gaseous $\mathrm{KCl}$. Ammonium sulphate was injected into the cyclone at three air excess ratios ( $\lambda=1.1,1.2$ and 1.4). Each measurement was carried out for $3 \mathrm{~h}$ and several measurement tools were applied including IACM, deposit probes, and conventional gas analysis. The measurements were performed for a reference case and two flows of AS (low flow (amount of AS) = ASL, high flow = ASH). The
Table 2

Fuel properties.

\begin{tabular}{lll}
\hline & Straw pellets & Wood chips \\
\hline Proximate analysis & & \\
Water (wt\%, raw) & 6.3 & 40.5 \\
Ash (wt\%, dry) & 5.1 & 0.9 \\
Combustibles (wt\%, dry) & 94.9 & 99.1 \\
Volatiles (wt\%, daf) & 80.1 & 81.7 \\
Ultimate analysis (wt\%, daf) & & \\
$\mathrm{C}$ & 49.4 & 50.0 \\
$\mathrm{H}$ & 6.2 & 6.0 \\
$\mathrm{O}$ & 43.5 & 43.7 \\
$\mathrm{~S}$ & 0.10 & 0.01 \\
$\mathrm{~N}$ & 0.58 & 0.15 \\
$\mathrm{Cl}$ & 0.29 & 0.01 \\
Ash analysis (g/kg dry ash) & & \\
$\mathrm{K}$ & 139 & 128 \\
$\mathrm{Na}$ & 3.9 & 6.6 \\
$\mathrm{Al}$ & 1.9 & 5.4 \\
$\mathrm{Si}$ & 250 & 31.6 \\
$\mathrm{Fe}$ & 1.8 & 4.9 \\
$\mathrm{Ca}$ & 65 & 234 \\
$\mathrm{Mg}$ & 14 & 28 \\
$\mathrm{P}$ & 11 & 15 \\
Ti & 0.1 & 0.3 \\
$\mathrm{Ba}$ & 0.7 & 1.7 \\
Lower heating value (MJ/kg) & & 10.7 \\
$\mathrm{H}$, daf & 18.4 & \\
$\mathrm{H}$, raw & 16.2 & \\
\hline & & \\
\hline
\end{tabular}

daf = Dry and ash free, raw $=$ as received.

corresponding molar flows and molar ratios of certain experimental parameters are shown in Table 4 .

The molar ratio $\mathrm{S} / \mathrm{Cl}$ is a measure to which degree a fuel mix is corrosive and is given for the total amount of sulphur from the fuel and AS for each test case. $\mathrm{S} / \mathrm{Cl}$ reflects the excess of sulphur in relation to chlorine and relates to the competition between $\mathrm{Cl}$ and $\mathrm{S}$ in reacting with $\mathrm{K}$. The risk of corrosion is often considered great at a molar ratio $\mathrm{S} / \mathrm{Cl}$ less than 2.0 and low at an $\mathrm{S} / \mathrm{Cl}$ ratio above 4.0. The chlorine content in the deposits could also be a measure of the risk 
Table 3

Experimental parameters and injection points for AS during the transient test at $\lambda=1.2$.

\begin{tabular}{lcllll}
\hline $\begin{array}{l}\text { Test case } \\
\text { injection } \\
\text { point }\end{array}$ & $\begin{array}{l}\text { Sulphur } \\
\text { mol/ } \\
\text { MWh }\end{array}$ & $\begin{array}{l}\text { S/Cl } \\
\text { molar } \\
\text { ratio }\end{array}$ & $\begin{array}{l}\text { Upper part } \\
\text { comb. chamber } \\
(17)\end{array}$ & $\begin{array}{l}\text { Inlet } \\
\text { cyclone } \\
(18)\end{array}$ & $\begin{array}{l}\text { Cyclone } \\
(19)\end{array}$ \\
\hline Ref-1.2 & 1.9 & 0.5 & $\mathrm{x}$ & $\mathrm{x}$ & $\mathrm{x}$ \\
AS1-1.2 & 4.9 & 1.2 & $-^{\mathrm{a}}$ & $\mathrm{x}$ & $\mathrm{x}$ \\
AS2-1.2 & 6.4 & 1.6 & $-^{\mathrm{a}}$ & $\mathrm{x}$ & $\mathrm{x}$ \\
AS3-1.2 & 7.9 & 1.9 & $\mathrm{x}$ & $\mathrm{x}$ & $\mathrm{x}$ \\
AS4-1.2 & 11.0 & 2.7 & $\mathrm{x}$ & $\mathrm{x}$ & $\mathrm{x}$ \\
AS5-1.2 & 14.0 & 3.4 & $\mathrm{x}$ & $\mathrm{x}$ & $\mathrm{x}$ \\
AS6-1.2 & 20.1 & 4.9 & $\mathrm{x}$ & $\mathrm{x}$ & $-^{\mathrm{a}}$ \\
\hline
\end{tabular}

a No test was included in the sequence at this flow during $\lambda=1.2$.

of corrosion and no chlorine was found when sulphur was available in the form of $\mathrm{SO}_{3}$ instead of $\mathrm{SO}_{2}$ at a molar ratio $\mathrm{S} / \mathrm{Cl}$ of 1.0 in [10] and 2.1 in [13]. Thus, the oxidation state of sulphur (i.e. $\mathrm{SO}_{2}$ or $\mathrm{SO}_{3}$ ) has an impact on the risk of corrosion. Consequently, the risk of corrosion could also be described with a distinction between molar ratios $\mathrm{S}_{\mathrm{SO} 3} / \mathrm{Cl}$ and $\mathrm{S}_{\mathrm{SO} 2} / \mathrm{Cl}$. Theoretically, a molar ratio $\mathrm{S} / \mathrm{K}$ of 0.5 is sufficient for complete sulphation of $\mathrm{K}$ to $\mathrm{K}_{2} \mathrm{SO}_{4}$. In practice, however, an excess of $\mathrm{S}$ is needed to prevent the formation of $\mathrm{KCl}$. Calcium (Ca) in the fuel ash is also reactive and can capture sulphur. Boström et al. [26] recently summarised ash transformation phenomena for biomass. Based on thermodynamic considerations only, $\mathrm{K}$ was found to be more reactive towards $\mathrm{S}$ than $\mathrm{Cl}$ and $\mathrm{S}$ more reactive towards $\mathrm{K}$ than $\mathrm{Ca}$. The chlorine content in the deposits was found to increase at molar ratios of $\mathrm{S} /(\mathrm{Ca}+2 \mathrm{~K}+2 \mathrm{Na})$ lower than 0.2 in the fuel during co-combustion of biomass with peat and coal [27]. The molar ratio $\mathrm{S} /(\mathrm{Ca}+2 \mathrm{~K}+2 \mathrm{Na})$ in the present project was below 0.2 during ASL and ranged from 0.18 to 0.25 for the highest flow (ASH). The calcium input load ranged between 13.4 and $16.7 \mathrm{~mol} / \mathrm{MWh}$ supplied energy, which corresponded to molar ratio $\mathrm{Ca} / \mathrm{S}$ of between 6.2 and 9.9 for the reference cases and between 1.2 and 1.9 for ASH. The molar ratio $\mathrm{Cl} /(\mathrm{K}+\mathrm{Na})$ is a measure of the amount of $\mathrm{Cl}$ available in relation to the alkali content of the fuel. It varied between 0.20 and 0.30 for the present test cases, implying insufficient $\mathrm{Cl}$ to form $\mathrm{KCl}$ even during co-combustion of wood chips and straw pellets. The alkali $(\mathrm{Na}+\mathrm{K})$ and chlorine input load in Table 4 ranged from 14.8 to $22.5 \mathrm{~mol} / \mathrm{MWh}$ and from 4.1 to $6.5 \mathrm{~mol} /$ MWh supplied energy respectively. The variation in alkali and chlorine input load was due to different fractions of straw in the fuel mix. As expected, the input load of S varied significantly, since most of the sulphur originated from ammonium sulphate.

\subsection{Measurement equipment}

A so-called IACM (In situ Alkali Chloride Monitor) located at (13) in Fig. 1 measured the alkali chlorides in the gas phase $[28,29]$.
IACM measures the sum of the $\mathrm{KCl}(\mathrm{g})$ and $\mathrm{NaCl}(\mathrm{g})$ concentrations on-line, but is unable to distinguish between these two species. The result is expressed as $\mathrm{KCl}$, which is the dominant gaseous alkali species at conditions prevailing in a CFB boiler during biomass combustion. A higher content of $\mathrm{K}$ in relation to $\mathrm{Na}$ is also presented in Table 2. IACM also measures $\mathrm{SO}_{2}$ simultaneously. A schematic view of IACM is shown in Fig. 2. Light from a xenon lamp is sent across the furnace or flue gas channel (measurement path). The light, which arrives at the receiver, is analysed by a spectrometer. IACM has been used in the present boiler in several previous projects related to alkali chloride issues in which it is described in more detail $[8,10,12,13,24,25,30]$. IACM is a part of the so-called ChlorOut concept. It consists of IACM and a sulphate-containing additive that converts alkali chlorides to less corrosive alkali sulphates [31]. The sulphate-containing additive is often ammonium sulphate, although several other sulphates are also included in the ChlorOut concept. One advantage with ammonium sulphate is that a significant $\mathrm{NO}_{x}$ reduction is achieved parallel to the sulphation of alkali chlorides [12].

Flue gas was extracted through a heated probe and heated sampling lines to an FTIR (Fourier Transform Infra-Red) analyser for the determination of $\mathrm{HCl}, \mathrm{SO}_{2}, \mathrm{H}_{2} \mathrm{O}, \mathrm{N}_{2} \mathrm{O}, \mathrm{NO}, \mathrm{NO}_{2}$ and $\mathrm{NH}_{3}$ on hot wet flue gases. The gas was further transported to on-line IR-VIS instruments measuring $\mathrm{CO}$ and $\mathrm{SO}_{2}$ on cold dry gases and a paramagnetic analyser for $\mathrm{O}_{2}$. A chemiluminescence analyser was used for NO and a flame ionisation detector (FID) for volatile hydrocarbons $\left(\mathrm{HC}_{\mathrm{tot}}\right)$ in connection to the cold system. Methane $\left(\mathrm{CH}_{4}\right)$ was used for calibration of the FID analyser and consequently $\mathrm{HC}_{\text {tot }}$ is presented as ppm methane equivalents. Gas concentrations were measured in locations after the convection path (22) and before the stack (23) during all test cases. Additional gas measurements were also carried out during the transient tests to characterise the composition of the flue gas without injection of AS at measurement locations (17), (18), (19), (20), (22) and (23) in Fig. 1.

The deposit measurements were carried out before the convection path in location (20) using a temperature controlled deposit probe. The gas temperature in (20) can be found in Table 1 (before conv. pass). Deposits were collected at a ring temperature of $500{ }^{\circ} \mathrm{C}$ after $3 \mathrm{~h}$ exposure on steel rings made of Sanicro 28, a high-alloyed Fe based steel. The deposits were analysed by wet chemistry (Inductive Coupled Plasma with Optical Emission Spectroscopy (ICP-OES) and Ion Chromatography (IC)). The chemical analysis by ICP-OES and IC was made on all the collected deposits on the ring.

\subsection{Modelling procedure}

Detailed reaction modelling of the $\mathrm{KCl}$ sulphation was performed to support the discussion of the experimental results. The modelling examines the capability of $\mathrm{SO}_{2}$ and $\mathrm{SO}_{3}$ to convert $\mathrm{KCl}$ into $\mathrm{K}_{2} \mathrm{SO}_{4}$ and the influence of volatile combustibles on the

Table 4

Experimental parameters when investigating the effect of $\mathrm{O}_{2}$ on the sulphation of $\mathrm{KCl}$.

\begin{tabular}{|c|c|c|c|c|c|c|}
\hline Test case & Load & $\begin{array}{l}\text { Chlorine } \\
\text { mol/MWh }\end{array}$ & $\begin{array}{l}\text { Alkali }(\mathrm{Na}+\mathrm{K}) \\
\mathrm{mol} / \mathrm{MWh}\end{array}$ & $\begin{array}{l}\text { Sulphur } \\
\text { mol/MWh }\end{array}$ & $\begin{array}{l}\mathrm{S} / \mathrm{Cl} \text { molar } \\
\text { ratio }\end{array}$ & $\begin{array}{l}\mathrm{S} /(\mathrm{Ca}+2 \mathrm{~K}+2 \mathrm{Na}) \\
\text { molar ratio }\end{array}$ \\
\hline Ref-1.1 & 6.5 & 4.1 & 14.8 & 1.9 & 0.5 & 0.04 \\
\hline ASL-1.1 & 6.4 & 4.5 & 15.9 & 6.5 & 1.4 & 0.14 \\
\hline ASH-1.1 & 6.6 & 4.2 & 14.8 & 10.7 & 2.5 & 0.25 \\
\hline Ref-1.2 & 6.1 & 4.1 & 18.8 & 1.9 & 0.5 & 0.03 \\
\hline ASL-1.2 & 5.8 & 5.0 & 22.4 & 7.1 & 1.4 & 0.11 \\
\hline ASH-1.2 & 5.9 & 4.1 & 20.5 & 11.7 & 2.8 & 0.18 \\
\hline Ref-1.4 & 5.4 & 5.6 & 18.8 & 2.4 & 0.4 & 0.06 \\
\hline ASL-1.4 & 5.3 & 6.5 & 21.8 & 8.1 & 1.3 & 0.14 \\
\hline ASH-1.4 & 5.3 & 6.5 & 21.8 & 13.6 & 2.1 & 0.23 \\
\hline
\end{tabular}




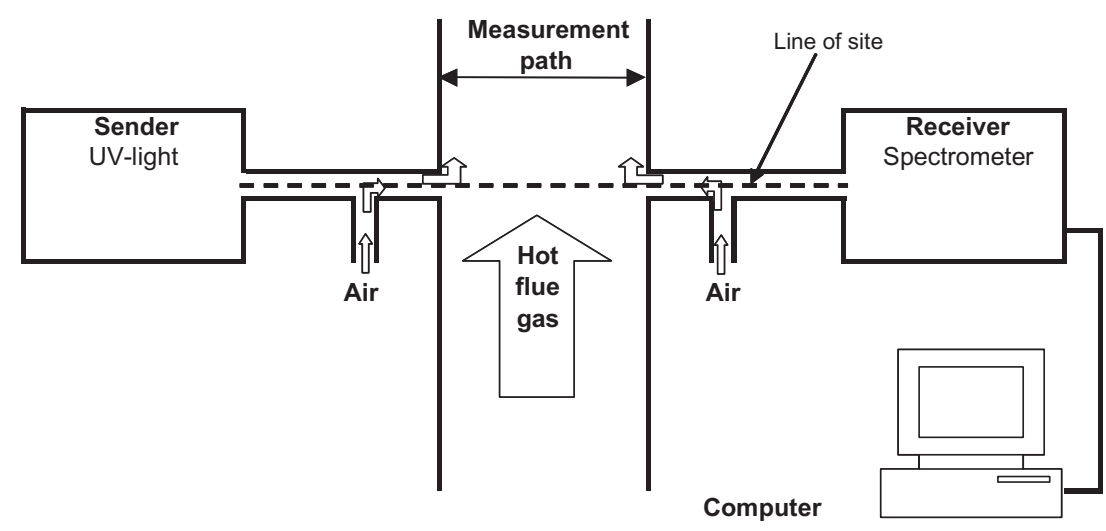

Fig. 2. Schematic view of an IACM installation.

sulphation capacity of $\mathrm{SO}_{3}$. The alkali/sulphur and combustion chemistry was modelled using two sets of detailed kinetic mechanisms.

The first mechanism (Mech A) is compiled by Hindiyarti et al. [14]. It is based on the model proposed by Glarborg and Marshal [19], which includes the reactions of importance for $\mathrm{K} / \mathrm{Cl} / \mathrm{S}$ chemistry and interactions with the radical pool of $\mathrm{OH}, \mathrm{O}$ and $\mathrm{H}$. Hindiyarti et al. [14] focused on updating the model with sulphation pathways not involving $\mathrm{SO}_{3}$ by including species such as $\mathrm{KHSO}_{3}$ and $\mathrm{KSO}_{4}$. Mech A has previously been compared with laboratory and entrained flow reactor experiments [14]. Furthermore, the present work aims to explore the influence of combustion on the sulphation of $\mathrm{KCl}$, which was measured in the experiments. A second mechanism (Mech B) was compiled to enable such an investigation. Mech $B$ is based on the model proposed in [14] (Mech A) and is updated with subsets for oxidation of $\mathrm{CO} / \mathrm{H}_{2}, \mathrm{CH}_{2} \mathrm{O}$ and $\mathrm{C}_{1}-\mathrm{C}_{2}$ hydrocarbons. The oxidation subsets were compiled and validated against a broad range of $\mathrm{CO}_{2}$ and $\mathrm{O}_{2}$ concentrations by Glarborg and Bendtsen [15]. Their mechanism is based mostly on work by previous authors on oxidation of $\mathrm{CO} / \mathrm{H}_{2}$ [32], $\mathrm{CH}_{2} \mathrm{O}$ [33], $\mathrm{CH}_{3} \mathrm{OH}$ [34], and $\mathrm{C}_{2}-\mathrm{C}_{3}$ hydrocarbons [35-39]. Mech $\mathrm{B}$ is compiled in the present work and has never been validated as whole, although the subsets are validated for their individual use. Mech $B$ is thus used to discuss the influence of combustibles on the $\mathrm{K} / \mathrm{Cl} / \mathrm{S}$ chemistry measured in the experiment.

The reactor model is a perfectly stirred reactor (PSR), which should represent the mixing conditions in the primary cyclone ( 8 in Fig. 1). Similar modelling based on experiments at the Chalmers boiler has previously been performed and the cyclone residence time estimated to be $0.5 \mathrm{~s}$ at $875^{\circ} \mathrm{C}[40,41]$. Please note that even though the modelling conditions are kept close to the experimental conditions, a qualitative rather than a quantitative comparison is sought. The inlet concentrations to the reactor are presented in

Table 5

Inlet concentrations (\% vol) to mechanisms Mech A and Mech B in the reactor model. The span for sulphur and combustibles shows the range of the parameter study in. In case of combustibles (Mech B) in the feed gas the oxygen concentration is adjusted to give the same outlet concentration.

\begin{tabular}{lll}
\hline Parameter/inlet concentration (\% vol) & Mech A & Mech B \\
\hline $\mathrm{N}_{2}$ & Level & Level \\
$\mathrm{H}_{2} \mathrm{O}$ & 10 & 10 \\
$\mathrm{KCl}$ & 1 & 1 \\
$\mathrm{SO}_{2}$ & $0-2$ & $0-2$ \\
$\mathrm{SO}_{3}$ & $0-2$ & $0-2$ \\
$\mathrm{O}_{2}$ & 5 & 5 (outlet) \\
$\mathrm{CH}_{4}$ & - & $0-2$ \\
$\mathrm{H}_{2}$ & - & $0-2$ \\
$\mathrm{CO}$ & - & $0-2$ \\
\hline
\end{tabular}

Table 5 and were chosen to be in the proximity of the values for which the mechanism is validated in [14]. The $\mathrm{S} / \mathrm{Cl}$ ratio is varied between zero and two with both $\mathrm{SO}_{2}$ and $\mathrm{SO}_{3}$ as sulphur source. The influence of combustibles is investigated by having $\mathrm{CH}_{4}, \mathrm{H}_{2}$,
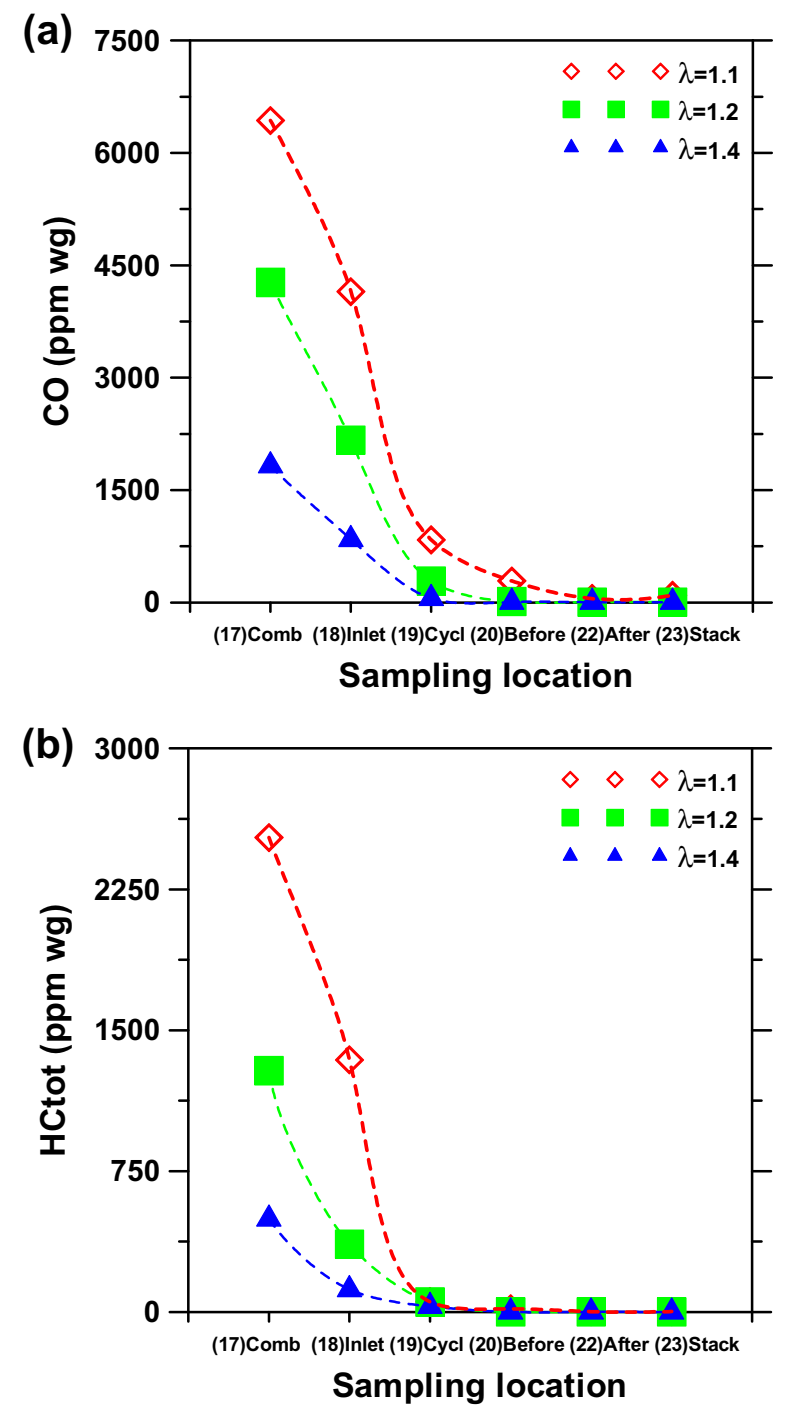

Fig. 3. $\mathrm{CO}$ (a) and $\mathrm{HC}_{\text {tot }}$ (b) versus sampling location at excess air ratios $\lambda=1.1,1.2$ and 1.4. The sampling locations were in the upper part of the combustion chamber (17 in Fig. 1), inlet of the cyclone (18), in the cyclone (19), before the convection pass (20); after the convection pass (22), and before the stack (23). 
and $\mathrm{CO}$ at the inlet. In case of combustibles at the inlet, $\mathrm{O}_{2}$ concentration is adjusted to be $5 \%$ after complete combustion. A residence time of $0.5 \mathrm{~s}$ is used as a base case, although the influence of residence times was investigated. The reactor is isothermal with a temperature of $1200 \mathrm{~K}$. The sensitivity of the reaction system to temperature was tested and found to be limited in the range of $1000-1300 \mathrm{~K}$.

\section{Results}

\subsection{Effect of combustibles - transient tests}

Increasing amounts of ammonium sulphate (AS) were injected in a sequence during the transient tests. AS was injected in three positions at excess air ratios $\lambda=1.1,1.2$ and 1.4. These positions were in the upper part of the combustion chamber (17 in Fig. 1), in the inlet of the cyclone (18), and in the cyclone (19). Injection in an earlier position such as (17) results in longer residence times
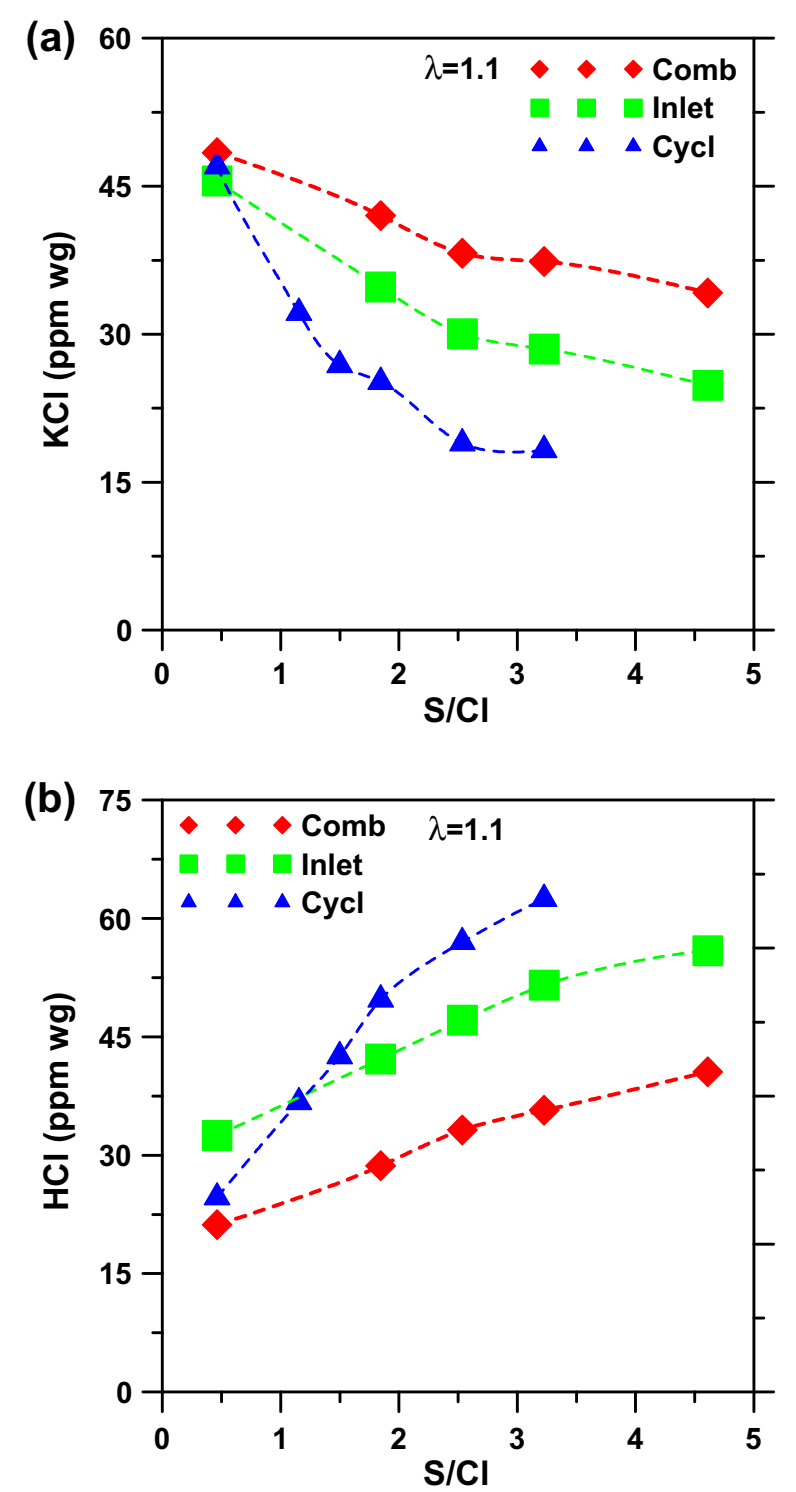

Fig. 4. Concentration of $\mathrm{KCl}$ (a) and $\mathrm{HCl}$ (b) versus molar ratio $\mathrm{S} / \mathrm{Cl}$ during the transient test at excess air ratio $\lambda=1$.1. AS was injected in the upper part of the combustion chamber (Comb, 17 in Fig. 1), in the cyclone inlet (Inlet, 18), and in the cyclone (Cycl, 19). for sulphation of gaseous $\mathrm{KCl}$. The purpose with the transient test was to study how the gas composition at the injection point of AS influenced the sulphation of gaseous $\mathrm{KCl}$. Since no additional secondary air is added after (5) in Fig. 1, the oxygen content was similar for the measurements during a specific air excess ratio. The presence of combustibles such as $\mathrm{CO}$, hydrogen $\left(\mathrm{H}_{2}\right)$, methane $\left(\mathrm{CH}_{4}\right)$, and ethene $\left(\mathrm{C}_{2} \mathrm{H}_{4}\right)$ that could interact with the sulphation of $\mathrm{KCl}$ varied with injection point.

Figure 3 shows the concentration of $\mathrm{CO}$ and $\mathrm{HC}_{\text {tot }}$ (volatile hydrocarbons) respectively at excess air ratios $\lambda=1.1,1.2$ and 1.4 at six measurement locations. The air excess ratio had a major impact on CO and the highest concentration (>6000 ppm) was found in the upper part of the combustion chamber at $\lambda=1.1$. The concentration of $\mathrm{CO}$ was nevertheless above $1000 \mathrm{ppm}$ during all air excess ratios in the upper part of the combustion chamber. $\mathrm{CO}$ was much lower in the inlet of the cyclone despite remaining above $1000 \mathrm{ppm}$ for $\lambda=1.1$, and 1.2. The level of CO in the cyclone ranged from $50 \mathrm{ppm}$ at $\lambda=1.4$ to approximately $800 \mathrm{ppm}$ at the lowest air excess ratio. The level of $\mathrm{HC}_{\mathrm{tot}}$, Fig. $3 \mathrm{~b}$, shows a similar pattern with the highest concentrations in the upper part of the combustion chamber, although only $50 \mathrm{ppm}$ or less remained in the cyclone. The main volatile hydrocarbons present were methane and ethene.

The concentration of gaseous $\mathrm{KCl}$ in Fig. 4a was approximately 45-50 ppm during each of the reference cases (Ref) without any injection at $\lambda=1.1$. $\mathrm{KCl}$ was reduced to approximately $30 \mathrm{ppm}$ during test case AS1 $(\mathrm{S} / \mathrm{Cl}=1.2)$ when injecting AS to the cyclone. A significantly greater amount of $\mathrm{AS}(\mathrm{S} / \mathrm{Cl}=2.5)$ was required to obtain a similar reduction in the cyclone inlet. The level of $\mathrm{KCl}$ was only lowered to approximately $35 \mathrm{ppm}$ during the highest flow of AS (AS6, S/Cl = 4.6) when injecting in the upper part of the combustion chamber.

The transient test revealed that the position had a great impact on the sulphation efficiency for gaseous $\mathrm{KCl}$. The injection point in the upper part of the combustion chamber is characterised by a higher concentration of both $\mathrm{CO}$ and $\mathrm{HC}_{\text {tot }}$ as can be seen in Fig. 3. The concentration of $\mathrm{SO}_{3}$ was thus limited by the presence of combustibles (i.e. $\mathrm{CO}$ and/or volatile hydrocarbons). Consequently, $\mathrm{SO}_{3}$ was partly consumed by other reactions than (R1) which lowered the sulphation efficiency. The sulphation of $\mathrm{KCl}$ was also more efficient during injection of AS at the higher air excess ratios $\lambda=1.2$ and 1.4 .

Sulphation of gaseous $\mathrm{KCl}(\mathrm{R} 1)$ results in an increase of $\mathrm{HCl}$ which shall resemble the reduction of $\mathrm{KCl}$ in $\mathrm{ppm}$. $\mathrm{HCl}$ was approximately $20-30$ ppm during Ref in Fig. $4 \mathrm{~b}$ and the greatest increase of $\mathrm{HCl}$ took place when injecting AS to the cyclone. Here, $\mathrm{HCl}$ increased with $32 \mathrm{ppm}$ and the corresponding decrease of $\mathrm{KCl}$ was $28 \mathrm{ppm}$ at a molar ratio $\mathrm{S} / \mathrm{Cl}$ of 2.5 . A slight difference between the increase of $\mathrm{HCl}$ and the decrease of $\mathrm{KCl}$ suggests gaseous sulphation of $\mathrm{KCl}$ rather than a heterogeneous reaction. The increase and corresponding decrease typically differed $2-5 \mathrm{ppm}$ during the transient tests at $\lambda=1.1$. The difference was similar or somewhat greater than it was at $\lambda=1.2$.

\subsection{Effect of oxygen - air-ratio tests}

\subsubsection{Sulphation of gaseous $\mathrm{KCl}$}

The presence of combustibles could interact with the effect of oxygen on the sulphation of gaseous $\mathrm{KCl}$ making the evaluation less obvious. The concentration of combustibles was lower in the cyclone in comparison with the upper part of the combustion chamber and in the cyclone inlet. Ammonium sulphate was consequently injected into the cyclone (19 in Fig. 1) and the air excess ratios were $\lambda=1.1,1.2$ and 1.4. The operating parameters for each air excess ratio are presented in Table 1 . The test cases were a reference case (Ref), and injection of low (ASL) and high (ASH) 
Table 6

Gas concentrations (recalculated to ppm dry gas @ 6\% $\mathrm{O}_{2}$ )

\begin{tabular}{|c|c|c|c|c|c|c|c|}
\hline Test case & $\mathrm{S} / \mathrm{Cl}$ molar ratio & $\mathrm{KCl}^{\mathrm{a}}(\mathrm{ppm})$ & $\mathrm{O}_{2}^{\mathrm{b}}(\%)$ & $\mathrm{SO}_{2}^{\mathrm{b}}(\mathrm{ppm})$ & $\mathrm{HCl}^{\mathrm{b}}(\mathrm{ppm})$ & $\mathrm{NO}^{\mathrm{c}}(\mathrm{ppm})$ & $\mathrm{CO}^{\mathrm{c}}(\mathrm{ppm})$ \\
\hline Ref-1.1 & 0.5 & 49 & 2.7 & 4 & 10 & 74 & 137 \\
\hline ASL-1.1 & 1.4 & 32 & 2.6 & 39 & 40 & 43 & 37 \\
\hline ASH-1.1 & 2.5 & 24 & 2.6 & 77 & 49 & 32 & 19 \\
\hline Ref-1.2 & 0.5 & 55 & 4.2 & 5 & 18 & 96 & 0 \\
\hline ASL-1.2 & 1.4 & 24 & 4.2 & 19 & 56 & 50 & 7 \\
\hline ASH-1.2 & 2.8 & 15 & 4.1 & 35 & 60 & 32 & 20 \\
\hline Ref-1.4 & 0.4 & 56 & 5.8 & 13 & 34 & 124 & 0 \\
\hline ASL-1.4 & 1.3 & 13 & 6.0 & 45 & 94 & 60 & 12 \\
\hline ASH-1.4 & 2.1 & 10 & 6.0 & 70 & 101 & 39 & 30 \\
\hline
\end{tabular}

a Measured at (20).

${ }^{b}$ Measured at (22).

c Measured at (23).

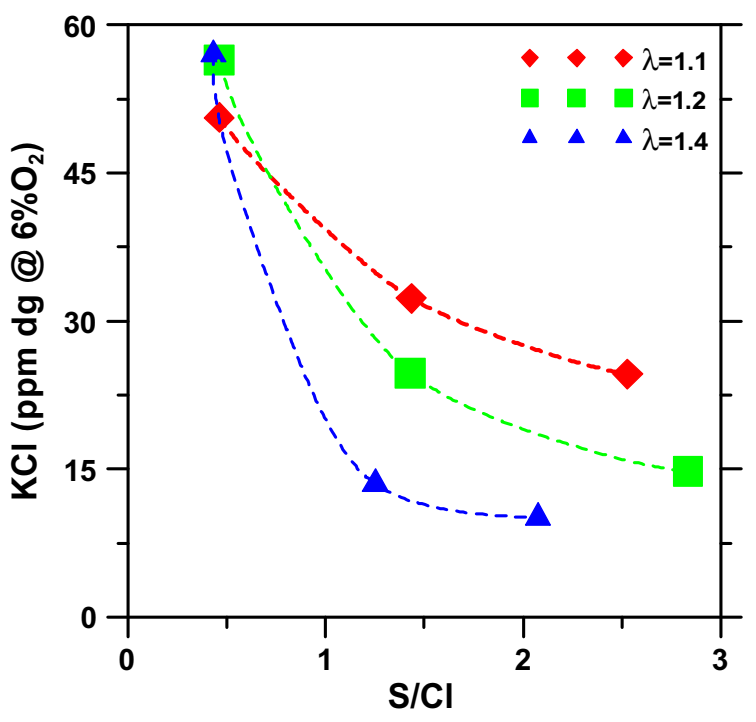

Fig. 5. $\mathrm{KCl}$ versus molar ratio $\mathrm{S} / \mathrm{Cl}$ during injection of $\mathrm{AS}$ in the cyclone at the three air excess air ratios $(--\lambda=1.1,--\lambda=1.2,--\lambda=1.4)$.

amount of AS for each $\lambda$. Ref, ASL and ASH corresponded to a molar ratio $\mathrm{S} / \mathrm{Cl}$ of $0.5,1.4$ and 2.8 respectively at $\lambda=1.2$. A selection of relevant molar flows and molar ratios for the different test cases is presented in Table 4.

Results obtained from IACM $(\mathrm{KCl})$ and gas analysis normalised to $6 \% \mathrm{O}_{2}$ are shown in Table 6 . Injection of ammonium sulphate resulted in a minor increase of $\mathrm{CO}$ at very low levels and this effect has previously been discussed in for instance [12]. The increase of CO only occurred when the initial level of CO was very low, whereas the trend was the reversed during $\lambda=1.1$. CO was well above $100 \mathrm{ppm}$ during Ref and it decreased drastically during injection of AS. The lowest level of CO was actually achieved during the lowest air excess ratio at ASH. This effect has previously been described in [42], in which AS was used both to lower NO and $\mathrm{CO}$ during combustion of biomass in a boiler with high emissions of $\mathrm{CO}$. The formation of NO was strongly favoured by an increasing air excess ratio. The reduction of NO by AS was, however, significantly greater at higher air excess ratios. This resulted in a similar final concentration of $\mathrm{NO}$ at ASH although the initial concentration for $\lambda=1.4$ was almost twice that for $\lambda=1.1$ during Ref. Further aspects on ammonium sulphate as an additive for NO reduction in comparison with ammonia and urea are treated in [12]. The concentration of $\mathrm{SO}_{2}$ measured after the convective pass at (22) increased when AS was injected. The greatest concentrations of $\mathrm{SO}_{2}$ were found at ASH during the highest and lowest air excess ratios.

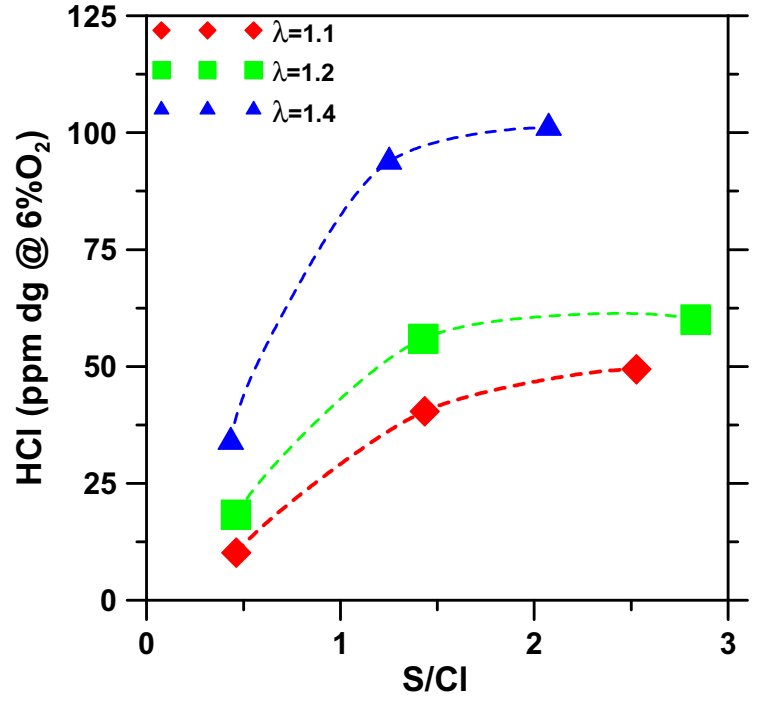

Fig. 6. $\mathrm{HCl}$ versus molar ratio $\mathrm{S} / \mathrm{Cl}$ during injection of $\mathrm{AS}$ in the cyclone at the three air excess air ratios $(--\lambda=1.1,--\lambda=1.2,--\lambda=1.4)$.

Figure 5 shows the concentration of gaseous $\mathrm{KCl}$ versus the molar ratio $\mathrm{S} / \mathrm{Cl}$. The $\mathrm{KCl}$ concentration was approximately $50 \mathrm{ppm}$ during the reference cases (Ref) at the different air excess ratios. $\mathrm{KCl}$ was reduced to $13 \mathrm{ppm}$ at a $\lambda$ of 1.4 and to $20 \mathrm{ppm}$ at a $\lambda$ of 1.2 during test case ASL. The reduction of $\mathrm{KCl}$ was less efficient during the lowest air excess ratio. Twice the amount of AS (ASH) was required for $\lambda=1.1$ to obtain a reduction similar to ASL at $\lambda=1.2$. The concentration of $\mathrm{O}_{2}$ had an impact on the sulphation efficiency when injecting ammonium sulphate in the cyclone. Reaction (R2) (or Reactions (R6)-(R8)) depends on the oxygen concentration. An increased formation of $\mathrm{SO}_{2}$ from $\mathrm{SO}_{3}$ at lower $\lambda$ could possibly explain the less efficient sulphation during the lower air excess ratios. The presence of combustibles could also have a considerable influence on the sulphation of $\mathrm{KCl}$. Figure 3a shows that the concentration of $\mathrm{CO}$ in the cyclone ranged from $50 \mathrm{ppm}$ at $\lambda=1.4$ to approximately $800 \mathrm{ppm}$ at the lowest air excess ratio. The presence of volatile hydrocarbons in the cyclone is shown in Fig. $3 \mathrm{~b}$ and $50 \mathrm{ppm}$ or less of $\mathrm{HC}_{\mathrm{tot}}$ remained. The low levels of $\mathrm{CO}$ and volatile hydrocarbons in the cyclone suggest that the results obtained were mainly an effect of the $\mathrm{O}_{2}$ concentration rather than combustibles.

Figure 6 shows the concentration of $\mathrm{HCl}$ measured after the convection pass (22 in Fig. 1). $\mathrm{HCl}$ is expected to increase during sulphation of $\mathrm{KCl}$ (R1) and a higher concentration was noticed during all test cases compared to the reference cases. The increase of $\mathrm{HCl}$ shall, according to (R1), correspond to the decrease in $\mathrm{KCl}$ 


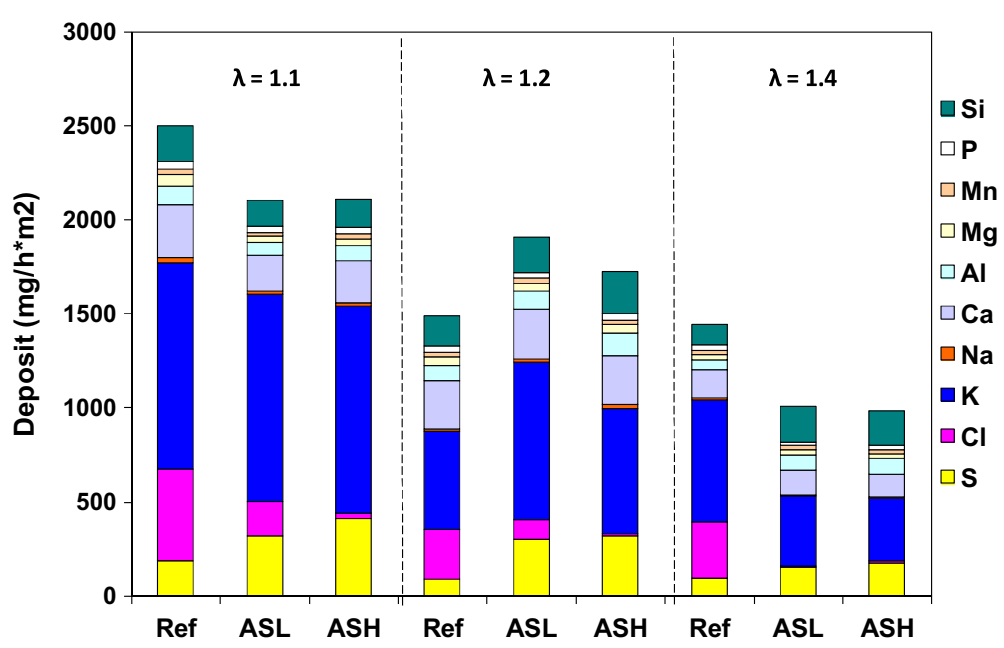

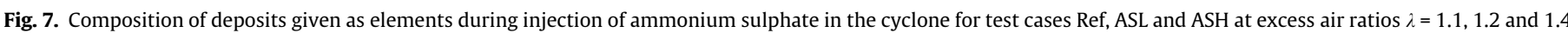
(of major elements $\mathrm{O}, \mathrm{C}$ and $\mathrm{Fe}$ are excluded).

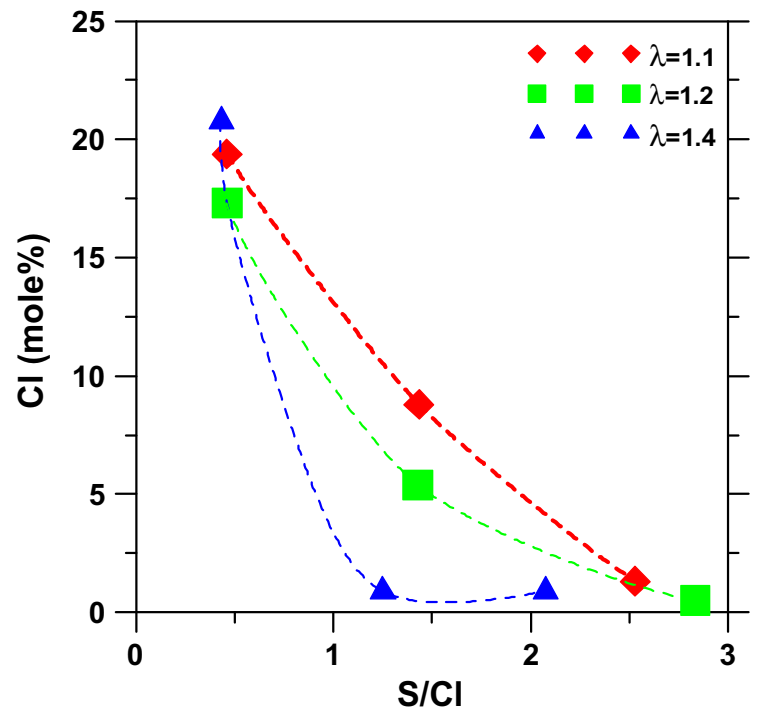

Fig. 8. Mole\% of chlorine $(\mathrm{Cl})$ in the deposits versus molar ratio $\mathrm{S} / \mathrm{Cl}$ during injection of ammonium sulphate in the cyclone at three different excess air ratios $(\lambda=1.1$, $1.2,1.4)$.

during gaseous sulphation of $\mathrm{KCl}$. A greater increase of $\mathrm{HCl}$ than decrease of gaseous $\mathrm{KCl}$ can be explained by gaseous sulphation between the measurement location for $\mathrm{KCl}(19)$ and that for $\mathrm{HCl}$ (22). It can also be explained by secondary sulphation of $\mathrm{KCl}$ condensed on particles or colder surfaces such as boiler tubes.

\subsubsection{Concentration of chlorine in the deposits}

Deposit measurements were also carried out for the test cases described in Table 4. Figure 7 shows the composition in deposits from the whole ring analysed by ICP-OES and IC (of major elements oxygen (O), carbon (C) and iron (Fe) are not included). The main elements in the deposits were sulphur, chlorine, potassium, calcium and silicon (Si). Ca and $\mathrm{Si}$ are not further discussed since injection of AS and the various excess air ratios had only limited effect on them. Significantly more chlorine and less sulphur were found in the deposits in the reference cases when no AS was injected during all $\lambda$. In general, the deposit growth rate in Fig. 7 was greater during lower excess air ratios and the injection of ammonium sulphate lowered the growth rate somewhat.

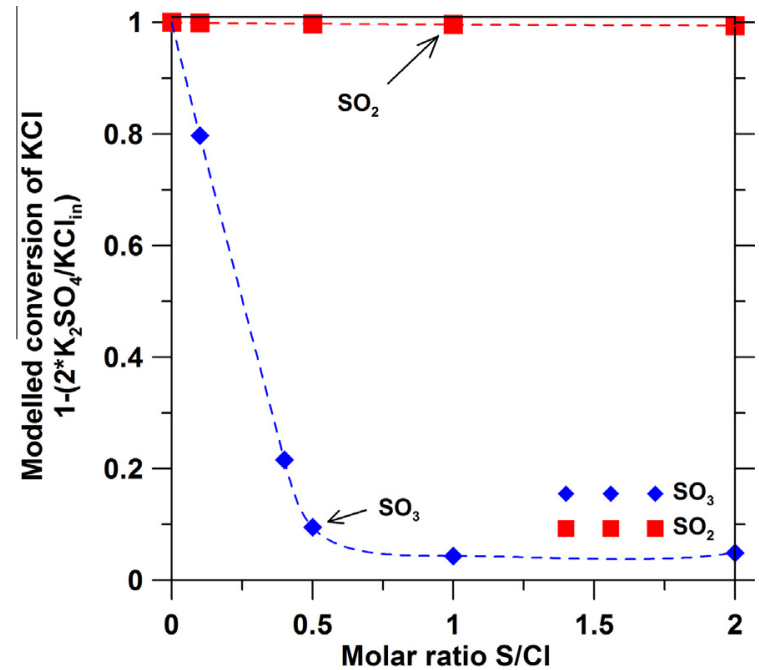

Fig. 9. The reduction of $\mathrm{KCl}$ versus the molar ratio $\mathrm{S} / \mathrm{Cl}$. (a) The reduction as modelled formation of $\mathrm{K}_{2} \mathrm{SO}_{4}$ using the first reaction mechanism set up. The reactor is modelled as a PSR with $0.5 \mathrm{~s}$ residence time. Mech A inlet conditions (Table 5) with increasing inlet concentration of $\mathrm{SO}_{2}$ and $\mathrm{SO}_{3}$ from 0 up to $2 \mathrm{vol} \%$ respectively (with the other species constant at $0 \mathrm{vol} \%$ ).

The mole\% of chlorine versus the molar ratio S/Cl during the Ref, ASL and ASH cases are shown in Fig. 8. The chlorine content in the deposits has an impact on the risk of corrosion and no chlorine indicates a lower risk $[10,25]$ The highest mole\% of $\mathrm{Cl}$ was found in the deposits without injection of ammonium sulphate. Significant amounts of $\mathrm{Cl}$ were also found during $\operatorname{ASL}(\mathrm{S} / \mathrm{Cl}=1.4)$ at air excess ratio $\lambda=1.1$. Nevertheless, only low amounts of chlorine remained during $\mathrm{ASH}(\mathrm{S} / \mathrm{Cl}=2.5)$ at $\lambda=1.1$. Chlorine was reduced although a significant concentration of $\mathrm{KCl}$ was measured by IACM suggesting a contribution from heterogeneous sulphation as well. No chlorine was detected in the deposits even at a molar $\mathrm{S} / \mathrm{Cl}$ of only 1.3 (ASL) during the highest $\lambda$. KCl present in the flue gas and in the deposit during Ref was already fully sulphated at ASL during $\lambda=1.4$ and only partly sulphated at ASL during $\lambda=1.1$. The sulphation was even somewhat better during ASL $(\lambda=1.4)$ than ASH during $\lambda=1.1$. The more efficient sulphation was achieved although the molar ratio $\mathrm{S} / \mathrm{Cl}$ was 2.5 at $\lambda=1.1$ and only 1.3 during $\lambda=1.4$. The mole\% of $\mathrm{S}$ increased in the deposits at increasing molar ratios $\mathrm{S} / \mathrm{Cl}$. However, it was not possible to identify any significant differences due to the air excess ratio. 


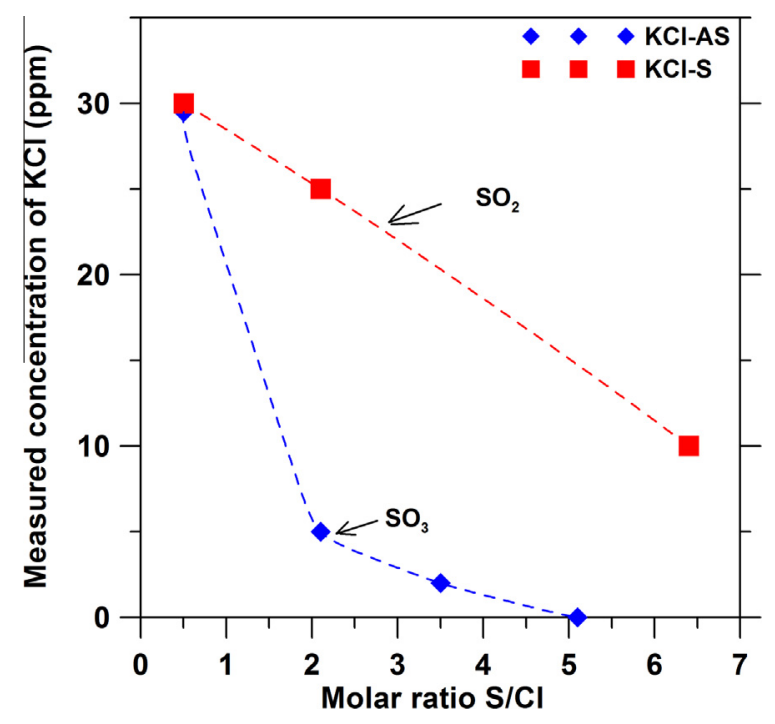

Fig. 10. The reduction as measured outlet $\mathrm{KCl}$ concentration in the Chalmers $\mathrm{CFB}$ boiler. $\mathrm{SO}_{3}$ added as ammonium sulphate at (18) in Fig. 1 and $\mathrm{SO}_{2}$ added as elemental sulphur at (14).

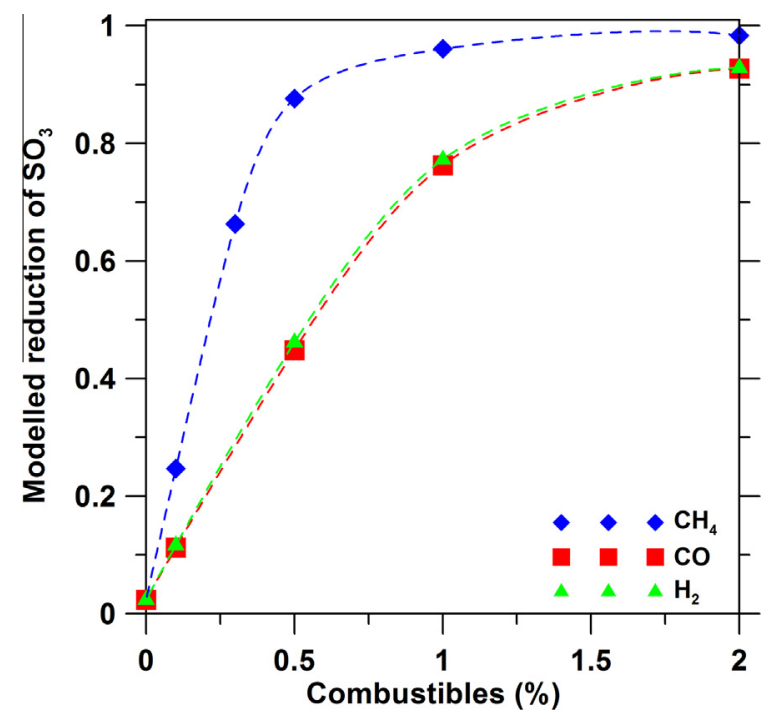

Fig. 11. Modelled reduction of $\mathrm{SO}_{3}$ versus the amount of combustibles added to the inlet stream. The reactor is modelled as a PSR with $0.5 \mathrm{~s}$ residence time. Mech $\mathrm{B}$ inlet conditions (Table 5) with increasing amount of $\mathrm{CH}_{4}, \mathrm{CO}$, and $\mathrm{H}_{2}$ from 0 up to 2 vol\% respectively (the other combustible species at $0 \mathrm{vol} \%$ ). The inlet oxygen concentration was adjusted to be 5 vol\% after complete combustion.

The results in Figs. 5 and 8 reveal a clear correlation between the sulphation of gaseous $\mathrm{KCl}$ and reduced chlorine content in the deposits in most test cases. This means on-line measurements of $\mathrm{KCl}$ by IACM can give a measure of the risk for increased chlorine content in the deposits during operation of a full-scale boiler.

\subsection{Sulphation chemistry - modelling}

\subsubsection{Importance of $\mathrm{SO}_{2}$ and $\mathrm{SO}_{3}$}

Figure 9 shows the modelled conversion of $\mathrm{KCl}$ into $\mathrm{K}_{2} \mathrm{SO}_{4}$ as a function of $\mathrm{S} / \mathrm{Cl}$ ratio with $\mathrm{SO}_{2}$ and $\mathrm{SO}_{3}$ as sulphur source in a perfectly stirred reactor using the Mech A mechanism (i.e. excluding combustibles) and inlet concentrations from Table 5 . It is obvious that the formation of $\mathrm{K}_{2} \mathrm{SO}_{4}$ is greater in the case of $\mathrm{SO}_{3}$ addition

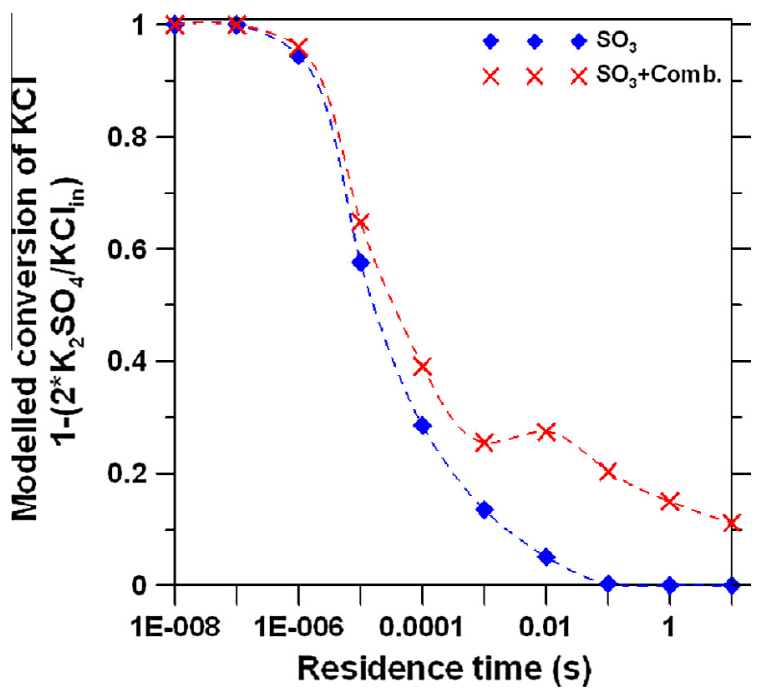

Fig. 12. Modelled conversion of $\mathrm{KCl}$ to $\mathrm{K}_{2} \mathrm{SO}_{4}$ versus residence time of the PSR. Combustibles inlet conditions (Table 5 ) with no combustibles or with 0.5 vol\% CO and $0.5 \mathrm{vol} \% \mathrm{H} 2$ at the inlet. Oxygen is adjusted to be 5 vol\% after complete combustion. The $\mathrm{S} / \mathrm{Cl}$ ratio is set to unity by adding $\mathrm{SO}_{3}$.

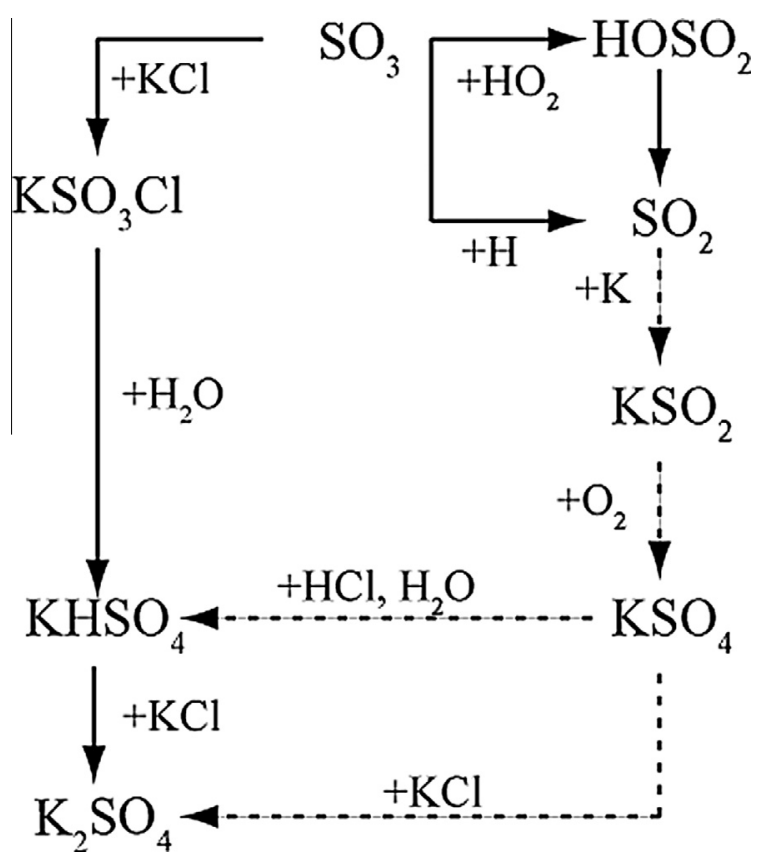

Fig. 13. Major reaction pathways of $\mathrm{SO}_{3}$ in the investigated system. Solid lines indicate paths of importance for the sulphation of $\mathrm{KCl}$ by $\mathrm{SO}_{3}$ and dashed lines indicate paths important for sulphation of $\mathrm{KCl}$ by $\mathrm{SO}_{2}$.

(blue) compared to $\mathrm{SO}_{2}$ addition (red). A similar investigation has been performed experimentally in the Chalmers CFB boiler by Kassman et al. [13]. The results of this investigation are presented in Fig. 10. Here, $\mathrm{SO}_{3}$ addition was represented by injection of $\mathrm{AS}$ at position (18) in Fig. 1 and $\mathrm{SO}_{2}$ addition by supply of elemental sulphur at position (14). There is a good qualitative agreement with the modelling; the experiments also show considerably higher reductions of $\mathrm{KCl}$ with $\mathrm{AS} / \mathrm{SO}_{3}$ addition. The higher $\mathrm{S} / \mathrm{Cl}$ ratios required in the experimental investigation is explained by imperfect mixing conditions and heterogeneous sulphur-consuming reactions in the CFB boiler. 




Fig. 14. Measured concentration of $\mathrm{KCl}$ versus molar ratio $\mathrm{S} / \mathrm{Cl}$ during the best (Cycl $\lambda=1.4$ ) and worst (Comb $\lambda=1.1$ ) combination of position and air excess ratio for reduction of gaseous $\mathrm{KCl}$. The combinations with similar reduction of $\mathrm{KCl}(\mathrm{Comb}$ $\lambda=1.4$, Inlet $\lambda=1.2$ and Cycl $\lambda=1.1$ ).

\subsubsection{Influence of combustibles}

Reduction of $\mathrm{SO}_{3}$ may be enhanced by oxidation of combustibles through the generation of chain carrying radicals, which increase the rate primarily of Reaction (R8). The reduction of $\mathrm{SO}_{3}$ during oxidation of $\mathrm{CH}_{4}, \mathrm{CO}$, and $\mathrm{H}_{2}$ was modelled by the second reaction mechanism setup (Mech $\mathrm{B}$ in Table 5). The reduction of an initial $\mathrm{SO}_{3}$ concentration of $1 \%$ after a residence time of $0.5 \mathrm{~s}$ is presented in Fig. 11. The reduction of $\mathrm{SO}_{3}$ is almost complete in a $1 \%$ mixture of $\mathrm{CH}_{4}$. The reduction is less pronounced with $\mathrm{CO}$ and $\mathrm{H}_{2}$, which has a lower impact on the radical formation, but a $2 \%$ mixture is sufficient for almost complete reduction also in this case. These results are in agreement with the results presented in Fig. 5 which showed a lower $\mathrm{KCl}$ reduction potential from $\mathrm{SO}_{3}$ in the presence of combustibles. The addition of hydrocarbons to the inlet stream simulates the case of $\mathrm{SO}_{3}$ (cf. AS in the experimental section) injection in a location of incomplete combustion. At this location the chemistry is complicated by the simultaneous oxidation of hydrocarbons and the reaction between $\mathrm{SO}_{3}$ and $\mathrm{KCl}(\mathrm{R} 1)$ has to compete with $\mathrm{SO}_{3}$ consumption by chain carrying radicals (R8).

Figure 12 shows the influence of combustibles ( 0.5 vol\% of $\mathrm{H}_{2}$ and $\mathrm{CO}$ ) on the sulphation of $\mathrm{KCl}$ by $\mathrm{SO}_{3}$. The residence time of the PSR is important for the relative reduction potential as can be seen in Fig. 12. The ignition delay of the combustibles used is about $0.01 \mathrm{~ms}$ and the effects of combustibles are therefore only seen for residence times above this. Figure 13 shows the major routes for sulphation by $\mathrm{SO}_{3}$ and $\mathrm{SO}_{2} . \mathrm{SO}_{3}$ may either react with $\mathrm{KCl}$ through the desired path to $\mathrm{K}_{2} \mathrm{SO}_{4}$ or with $\mathrm{H}$ and $\mathrm{HO}_{2}$ radicals forming $\mathrm{SO}_{2}$. The addition of hydrocarbons reduces $\mathrm{SO}_{3}$, and thus has a negative effect on the sulphation. This could be seen to some extent in Fig. 12. However, the effect is not as pronounced as could be expected by looking at the difference in sulphation efficiency between $\mathrm{SO}_{2}$ and $\mathrm{SO}_{3}$ (Fig. 9).

The relatively high modelled sulphation rate in presence of hydrocarbons is caused by a route proposed by Hindiyarti et al. [14] for $\mathrm{SO}_{2}$ to sulphate $\mathrm{KCl}$ through the formation of $\mathrm{KSO}_{4}$ (dotted line in Fig. 13), which is activated by the presence of hydrocarbons. In this case $\mathrm{SO}_{2}$ reacts with $\mathrm{K}$ formed in reaction between $\mathrm{KCl}$ and $\mathrm{H}$-radicals. The experimental result, however, revealed that the reduction of $\mathrm{SO}_{3}$ by combustibles has a considerable impact on the sulphation. The discrepancy could possibly be caused by model assumptions (e.g. residence time, mixing conditions, species concentrations). A more probable explanation is that the combination of the mechanism for $\mathrm{K} / \mathrm{Cl} / \mathrm{S}$ chemistry with the mechanism for combustion in Mech $\mathrm{B}$ triggered an exaggerated response on the $\mathrm{SO}_{2}$ sulphation capacity. This requires further investigation.

\section{Discussion}

The sulphation of gaseous $\mathrm{KCl}$ was compared in a technical scale CFB boiler during addition of elemental sulphur $\left(\mathrm{SO}_{2}\right)$ and sulphur in the form of ammonium sulphate $\left(\mathrm{SO}_{3}\right)$, and it was concluded that the sulphation rate of $\mathrm{SO}_{3}$ is superior to that of $\mathrm{SO}_{2}$ [13]. This conclusion is confirmed by detailed reaction modelling of the $\mathrm{K} / \mathrm{Cl} / \mathrm{S}$ chemistry in Fig. 9. The tendency of $\mathrm{SO}_{3}$ to be reduced to $\mathrm{SO}_{2}$ in certain combustion environments (high concentration of combustibles and low of oxygen) is thus also of great importance for the efficiency of AS for reduction of gaseous $\mathrm{KCl}$.

The results from IACM measurements revealed that the sulphation of gaseous $\mathrm{KCl}$ was less efficient when ammonium sulphate was injected in the upper part of the combustion chamber and during lower air excess ratios. An earlier position, such as the upper part of the combustion chamber, gives a less efficient sulphation although the residence time is longer in comparison with the other positions during the same air excess ratio. The burn-out of combustibles is, however, more complete in the downstream positions, which leads to fewer interactions for $\mathrm{SO}_{3}$ with the $\mathrm{O} / \mathrm{H}$ radical pool. The modelling shows that $\mathrm{SO}_{3}$ is almost completely reduced in the presence of a certain amount of combustibles ( $<1 \%$ ). When comparing Figs. 5 and 7 , it is observed that the position seems to have a greater impact on the sulphation efficiency of $\mathrm{KCl}$ than the air excess ratio.

Figure 14 shows $\mathrm{KCl}$ versus molar ratio $\mathrm{S} / \mathrm{Cl}$ during the best and worst combination of position and air excess ratio. It also shows that a similar reduction of $\mathrm{KCl}$ can be achieved at three positions by a combination of position and air excess ratio. The reduction of gaseous $\mathrm{KCl}$ was similar in the upper part of the combustion chamber at $\lambda=1.4$, in the inlet of the cyclone at $\lambda=1.2$ and in the cyclone at $\lambda=1.1$. The most efficient sulphation was achieved during injection of AS in the cyclone at $\lambda=1.4$ whereas the poorest sulphation was in the upper part of the combustion chamber at $\lambda=1.1$. The most efficient point is characterised by sufficiently high concentration of $\mathrm{O}_{2}$ and low concentration of volatile combustibles. According to the modelling, this minimises the reduction of $\mathrm{SO}_{3}$ to $\mathrm{SO}_{2}$ (R2) from reactions with $\mathrm{H}$ radicals (R8). The lowest efficiency point in the upper part of the combustion chamber is characterised by rather low concentration of $\mathrm{O}_{2}$ and the presence of volatile combustibles, such as $\mathrm{CO}$, methane and ethene. These conditions increase the reduction of $\mathrm{SO}_{3}$ to $\mathrm{SO}_{2}(\mathrm{R} 2)$ from reactions with $\mathrm{H}$ radicals ( $\mathrm{R} 8$ ).

The results in Fig. 14 were compared with the modelling in Fig. 9 and the measurements in Fig. 10, which shows the reduction of $\mathrm{KCl}$ when using ammonium sulphate (i.e. $\mathrm{SO}_{3}$ ) and sulphur (i.e. $\mathrm{SO}_{2}$ ). The performance of AS during injection in the lowest efficiency point resembles the sulphation efficiency for $\mathrm{KCl}$ when adding sulphur rather than $\mathrm{AS}$ in an appropriate position. The formation of $\mathrm{SO}_{2}$, according to ( $\mathrm{R} 8$ ) from $\mathrm{SO}_{3}$ and $\mathrm{H}$ radicals, is a fast reaction while the oxidation of $\mathrm{SO}_{2}$ to $\mathrm{SO}_{3}(\mathrm{R} 2)$ is slow. It is thus of great importance with appropriate positions and conditions for injection of ammonium sulphate in a full-scale boiler, which may be identified by measuring $\mathrm{KCl}$ with IACM.

\section{Conclusions}

The sulphation of gaseous $\mathrm{KCl}$ was investigated during injection of ammonium sulphate (AS) for three air excess ratios $(\lambda=1.1,1.2$ 
and 1.4). AS was injected at three positions: in the upper part of the combustion chamber, in the cyclone inlet and in the hot cyclone. Two experimental procedures focusing on the effect of combustibles (i.e. CO and/or volatile hydrocarbons) and oxygen were applied. The results from several measurement tools including IACM, deposit probes and gas analysis were evaluated. The main conclusions are summarised below:

- The AS injection position and stoichiometric ratio in the boiler had a great impact on the sulphation efficiency for gaseous $\mathrm{KCl}$. The optimal position and conditions were identified by measuring $\mathrm{KCl}$ with IACM.

- The injection point for AS in the upper part of the combustion chamber at the lowest air excess ratio $(\lambda=1.1)$ had the lowest sulphation of $\mathrm{KCl}$ and the highest concentrations of combustibles. Modelling shows that $\mathrm{SO}_{3}$ is reduced to $\mathrm{SO}_{2}$ in the presence of combustibles.

- The injection point for AS with the best performance for sulphation of $\mathrm{KCl}$ was in the cyclone during the highest air excess ratio $(\lambda=1.4)$. Here the concentration of combustibles and thus reduction of $\mathrm{SO}_{3}$ to $\mathrm{SO}_{2}$ were minimised.

- The concentration of oxygen influences the sulphation efficiency when injecting AS in the cyclone. Less gaseous $\mathrm{KCl}$ was reduced during air excess ratio $\lambda=1.1$ compared to the higher air excess ratios.

- Injection of AS decreases the mole\% of chlorine in the deposits. Significant amounts of $\mathrm{Cl}$ were present during AS injection at a $\mathrm{S} / \mathrm{Cl}$ molar ratio of 1.4 at $\lambda=1.1$. No $\mathrm{Cl}$ was detected in the deposits at an $\mathrm{S} / \mathrm{Cl}$ of 1.3 at $\lambda=1.4$.

- The sulphation of gaseous $\mathrm{KCl}$ correlates with reduced chlorine content in the deposits.

\section{Acknowledgments}

The main financial support for this work was provided by the Swedish Energy Administration. The additional support from Vattenfalĺs R\&D project "Biomass utilization" is appreciated. The practical support from the research engineers employed at Chalmers University of Technology is greatly appreciated. Furthermore, the authors would like to acknowledge Akademiska Hus AB for maintaining and operating the boiler.

\section{References}

[1] M. Theis, B.J. Skrifvars, M. Zevenhoven, M. Hupa, H.H. Tran, Fuel 85 (2006) 1992-2001.

[2] S.C. van Lith, F.J. Frandsen, M. Montgomery, T. Vilhelmsen, S.A. Jensen, Energy Fuels 23 (2009) 3457-3468.

[3] S.C. van Lith, V. Alonso-Ramirez, P.A. Jensen, F.J. Frandsen, P. Glarborg, Energy Fuels 20 (2006) 964-978.

[4] L.L. Baxter, T.R. Miles, B.M. Jenkins, T. Milne, D. Dayton, R.W. Bryers, L.L. Oden, Fuel Process. Technol. 54 (1998) 47-78.

[5] P. Glarborg, Proc. Combust. Inst. 31 (2007) 77-98.

[6] M. Aho, E. Ferrer, Fuel 84 (2005) 201-212.

[7] H. Kassman, M. Broström, M. Berg, L.-E. Åmand, Fuel 90 (2011) 1325-1334.
[8] A.L. Elled, K.O. Davidsson, L.-E. Åmand, Biomass Bioenergy 34 (2010) 15461554.

[9] R.A. Khalil, E. Housfar, W. Musinguzi, M. Becidan, Ø. Skreiberg, F. Goile, T. Løvås, L. Sørum, Energy Fuels 25 (2011) 2687-2695.

[10] H. Kassman, J. Pettersson, B.-M. Steenari, L.-E. Åmand, Fuel Process. Technol. 105 (2013) 170-180.

[11] P. Henderson, C. Andersson, H. Kassman, VGB PowerTech 84 (2004) 58-62.

[12] H. Kassman, M. Holmgren, E. Edvardsson, L.-E. Åmand, J. Öhlin, Nitrogen containing additives for simultaneous reduction of $\mathrm{KCl}$ and $\mathrm{NOx}$ during biomass combustion in a CFB boiler, in: 9th International Conference on Circulating Fluidized Beds, Hamburg, Germany, 2008.

[13] H. Kassman, L. Bäfver, L.-E. Åmand, Combust. Flame 157 (2010) 1649-1657.

[14] L. Hindiyarti, F. Frandsen, H. Livbjerg, P. Glarborg, P. Marshall, Fuel 87 (2008) 1591-1600.

[15] P. Glarborg, L.L.B. Bentzen, Energy Fuels 22 (2008) 291-296.

[16] K. Schofield, Combust. Flame 159 (2012) 1987-1996.

[17] J.R. Jensen, L.B. Nielsen, C. Schultz-Møler, S. Wedel, H. Livbjerg, Aerosol Sci. Technol. 33 (2000) 490-509.

[18] S. Jimenez, J. Ballester, Fuel 86 (2007) 486-493.

[19] P. Glarborg, P. Marshall, Combust. Flame 141 (2005) 22-39.

[20] K.A. Christensen, M. Stenholm, H. Livbjerg, J. Aerosol Sci. 29 (1998) 421-444.

[21] L. Hindiyarti, F. Frandsen, H. Livbjerg, P. Glarborg, Fuel 85 (2006) 978-988.

[22] D. Fleig, M.U. Alzueta, F. Normann, M. Abián, K. Andersson, F. Johnsson, Combust. Flame 160 (2013) 1142-1151.

[23] L. Hindiyarti, P. Glarborg, P. Marshall, J. Phys. Chem. A 111 (2007) 3984-3991.

[24] K.O. Davidsson, L.E. Åmand, B.M. Steenari, A.L. Elled, D. Eskilsson, B. Leckner, Chem. Eng. Sci. 63 (2008) 5314-5329.

[25] H. Kassman, Strategies to reduce gaseous $\mathrm{KCl}$ and chlorine in deposits during combustion of biomass in fluidised bed boilers, in: Department of Energy and Environment, PhD, Chalmers University of Technology, 2012.

[26] D. Boström, N. Skoglund, A. Grimm, C. Boman, M. Öhman, M. Broström, R. Backman, Energy Fuels 26 (2012) 85-93.

[27] P. Yrjas, B.J. Skrifvars, M. Hupa, J. Roppo, M. Nylund, P. Vainikka, Chlorine in deposits during co-firing of biomass, peat, and coal in a full-scale CFBC boiler, in: Proceedings of the 18th International Conference on Fluidized Bed Combustion, Toronto, Canada, 2005, pp. 679-687.

[28] European Patent EP 1221036, 2006.

[29] C. Forsberg, M. Broström, R. Backman, E. Edvardsson, S. Badiei, M. Berg, H. Kassman, Rev. Sci. Instrum. 80 (2009).

[30] H. Kassman, C. Andersson, J. Högberg, L.-E. Åmand, K. Davidsson, Gas phase alkali chlorides and deposits during co-combustion of coal and biomass, in: 19th International Conference on Fluidized Bed Combustion, Vienna, Austria, 2006.

[31] European Patent EP 1354167, 2006.

[32] C.L. Rasmussen, J. Hansen, P. Marshall, P. Glarborg, Int. J. Chem. Kinet. 40 (2008) 454-480.

[33] P. Glarborg, M.U. Alzueta, K. Kjærgaard, K. Dam-Johansen, Combust. Flame 132 (2003) 629-638.

[34] C.L. Rasmussen, K.H. Wassard, K. Dam-Johansen, P. Glarborg, Int. J. Chem. Kinet. 40 (2008) 423-441.

[35] M.S. Skjøth-Rasmussen, P. Glarborg, M. Østberg, J.T. Johannessen, H. Livbjerg, A.D. Jensen, T.S. Christensen, Combust. Flame 136 (2004) 91-128.

[36] M.S. Skjøth-Rasmussen, P. Glarborg, M. Østberg, M.B. Larsen, S.W. Sørensen, J.E. Johnsson, A.D. Jensen, T.S. Christensen, Proc. Combust. Inst. 29 (2002) 1329-1336.

[37] P. Glarborg, M.U. Alzueta, K. Dam-Johansen, J.A. Miller, Combust. Flame 115 (1998) $1-27$.

[38] A.B. Bendtsen, P. Glarborg, K. Dam-Johansen, Combust. Sci. Technol. 151 (2000) 31-71.

[39] C.L. Rasmussen, J.O.N. Geest Jakobsen, P. Glarborg, Int. J. Chem. Kinet. 40 (2008) 778-807.

[40] L. Gustavsson, P. Glarborg, B. Leckner, Combust. Flame 106 (1996) 345358.

[41] B. Leckner, M. Karlsson, K. Dam-Johansen, C.E. Weinell, P. Kilpinen, M. Hupa, Ind. Eng. Chem. Res. 30 (1991) 2396-2404.

[42] H. Kassman, C. Andersson (Forsberg), J. Carlsson, U. Björklund, B. Strömberg, Decreased Emissions of $\mathrm{CO}$ and NOx by Injection of Ammonium Sulphate into the Combustion Chamber, Värmeforsk Report No. 908 (Summary in English), 2005. 